\title{
Experimental evaluation of dynamic properties of an incrementally prestressed concrete girder railway bridge
}

\author{
S. I. Kim ${ }^{1}$, I. H. Yeo ${ }^{1}$, N. S. Kim ${ }^{2}$, J. W. Kwark ${ }^{3}$ \& J. S. Lee \\ ${ }^{1}$ Korea Railroad Research Institute, Republic of Korea \\ ${ }^{2}$ Pusan National University, Republic of Korea \\ ${ }^{3}$ DKorea Institute of Construction Technology, Republic of Korea
}

\begin{abstract}
The estimation of exact dynamic behavior is very important in railway bridges which can undergo resonance state from repetitive moving axle forces with uniform intervals. The dynamic interaction between bridge superstructures and passing trains is one of the critical issues concerning newly developed bridges designed with more flexibility. Therefore, it is very important to evaluate the modal parameters of PSC girders that have been newly designed before doing dynamic analyses. In this paper, a full scale incrementally prestressed concrete girder of 25 meters long as a test specimen was fabricated and modal testing on it at every prestressing stage was carried out to evaluate the modal parameters, including the natural frequency and the modal damping ratio. Young's modulus was also obtained from global stiffness of the test specimen. During the modal testing, a digitally controlled vibration exciter as well as an impact hammer is applied, in order to obtain precise frequency response functions, and the modal parameters were evaluated with various construction stages.

Keywords: railway bridge, modal test, dynamic performance estimation, moving train analysis.
\end{abstract}

\section{Introduction}

Repetitive moving forces with uniform intervals induced from a passing train can cause some undesirable behavior of railway bridges. The resonance of a structure can be broken out when the natural frequency of the bridge coincides with the 
exciting frequency of moving forces. For that reason, an exact application of the dynamic properties of a structure will lead to an exact understanding of the dynamic behavior of a structure under moving train loads.

As an alternative of conventional prestressed concrete girders, various types of PSC girders are being developed for, and applied in, as roadway and railway bridges. Incrementally prestressed concrete girder (IPC) and concrete girders with encased steel I-shaped beams are two representative types of these newly developed girders. According to the design concept, these new types of PSC girders have considerable advantages in terms of weight, while presenting the capability of creating longer spans. However, the dynamic interaction between bridge superstructures and passing trains is one of the critical issues concerning these railway bridges that have been designed with more flexibility. Therefore, it is very important to evaluate the modal parameters of PSC girders that have been newly designed before doing dynamic analyses.

The investigation of the dynamic behavior of bridges under moving loads dates back many years. During the past three decades, numerous experimental and theoretical study on moving loads problem of bridges has been carried out from early studies (Fryba, [3]) to recent studies (Yang et al. [6], Kwark et al. [4]). From simple concentrated force simulation to sophisticated interaction, various vehicle-bridge models and analysis methods have been implemented for more precise verification of the dynamic behavior of bridges under moving roadway or railway loads. However, most of experimental studies and theoretical studies are not related effectively. In the present study, dynamic properties from modal test of a full-scale girder are tried to be linked with the bridge-train interaction analysis for the estimation of dynamic performances.

A 25-meter-long full scale IPC girder as a test specimen was fabricated and modal testing on it at every prestressing stage was carried out to evaluate the modal parameters including the natural frequency and modal damping ratio. Young's modulus was also obtained from static loading tests. During the modal testing, a digitally controlled vibration exciter as well as an impact hammer is utilized, in order to obtain precise frequency response functions, and the modal parameters were evaluated with various construction stages.

The sectional and material properties of design values can have a number of differences compared to what is actual constructed, and the damping ratio of a structure cannot but depend on assumption particularly. Thus, an understanding of the exact dynamic behavior of railway bridges should be started from the exact modal properties of an applied bridge.

\section{Modal tests of an incrementally prestressed girder}

\subsection{General}

For the purpose of observing the modal properties of an IPC girder, modal experiments were performed sequentially, as shown in table 1. Experiments from Test I to Test IV were conducted in order to consider structural state changes according to the construction stages of an IPC girder. Test V was performed to 
verify the mode shapes from the impact hammer. During the modal testing, a vibration exciter that was controlled digitally was utilized, as was the impact hammer, in order to obtain the frequency response functions more accurately. Figure 1 shows a complete view of a $25 \mathrm{~m}$ full scale IPC girder model, a cross section of an IPC girder, and five channels of accelerometers and a LVDT used in experiments.

Table 1: Modal tests procedure.

\begin{tabular}{c|c|c}
\hline $\begin{array}{c}\text { Test } \\
\text { Case }\end{array}$ & Structural Condition & Vibration Source \\
\hline Test I & PSC girder only tensioned with bottom & Hammer \\
tendons & PSC girder with slab composition & $\begin{array}{c}\text { Hammer \& } \\
\text { Exciter }\end{array}$ \\
\hline Test II & $\begin{array}{c}\text { Hammer } \\
\text { tendons }\end{array}$ & $\begin{array}{c}\text { Hammer \& } \\
\text { Exciter }\end{array}$ \\
\hline Test IV & IPC girder complete stages & Hammer \\
\hline Test V & Mode shape configuration & \\
\hline
\end{tabular}
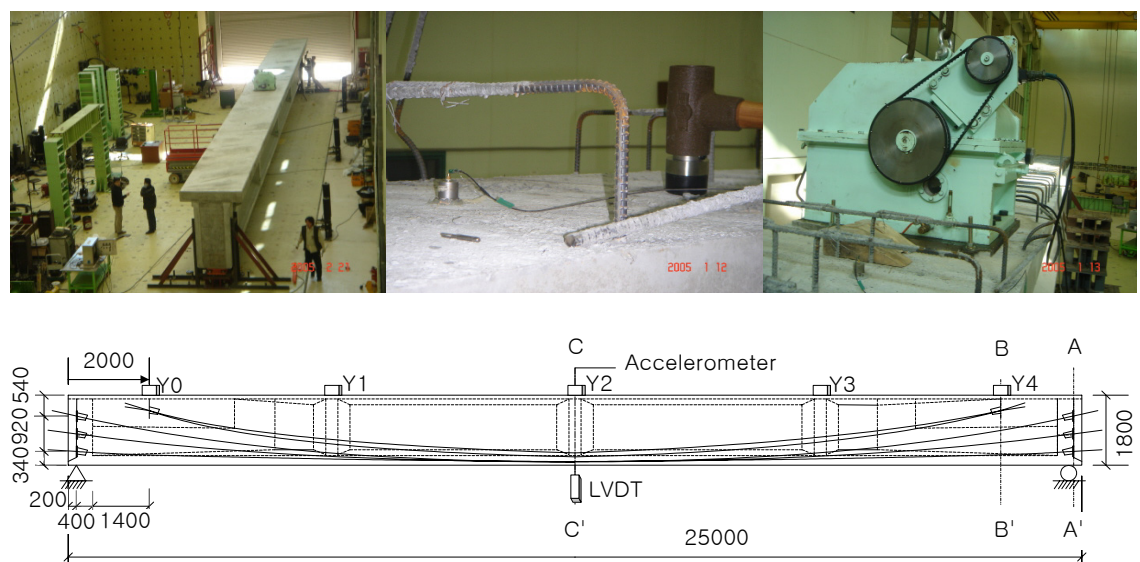

Figure 1: A complete view and location of sensors.

In figure $1, \mathrm{Y}_{0}$ and $\mathrm{Y}_{4}$ are used only in Test $\mathrm{V}$, which is performed in order to examine the mode shapes resulting from the impact hammer test. The mass of the impact hammer was $5.5 \mathrm{~kg}$, and its frequency range was $0 \sim 250 \mathrm{~Hz}$. The vibration exciter was composed of two unbalanced masses of $100 \mathrm{~kg}$ each, and had a frequency range of $0 \sim 12 \mathrm{~Hz}$. The sampling rate of the tests was set to be $500 \mathrm{~Hz}$ for each channel. The time interval $\Delta t$ can be determined by sampling 
frequency $f_{A}$ as shown in eq. (1), and the frequency resolution $\Delta f$ in the frequency domain can be acquired with the sampling data number $N$, as shown in eq. (2).

$$
\begin{gathered}
\Delta t=1 / f_{A} \\
\Delta f=1 /(N \times \Delta t)
\end{gathered}
$$

\subsection{Evaluation of modal properties}

A $25 \mathrm{~m}$ full scale IPC girder for a railway bridge was fabricated and tested before the estimation of the dynamic performance under moving train loads. The natural frequency and damping ratio were evaluated from the modal experiments by the impact hammer and vibration exciter. The impacts by the impact hammer numbered $15 \sim 25$ at the $\mathrm{L} / 4$ and $\mathrm{L} / 2$ points for each test. The vibration exciter is excited at the $\mathrm{L} / 2$ position of the model.

Figure 2 shows APSD functions (Bendat and Piersol [1]) at each accelerometer, which were acquired from the impact hammer's actions. The damping ratio can be evaluated by a half-power band width method from APSD functions. Figure 3 shows another response by the vibration exciter. In a resonance test by the vibration exciter, a sine sweeping was performed to cause a resonance state, and steady-state response could be acquired from the resonance frequency. The time history of each accelerometer from the resonance frequency was a free vibration response. The damping ratio was evaluated using the logarithmic decrement method.
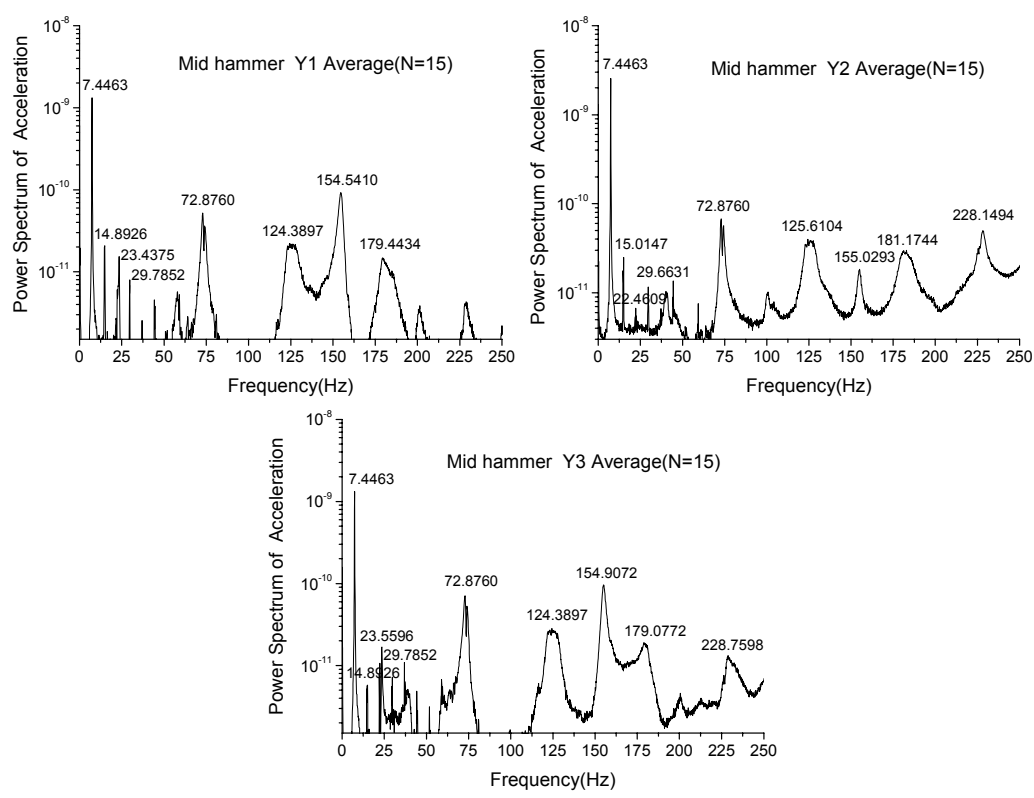

Figure 2: $\quad$ APSD functions at $\mathrm{Y}_{1}, \mathrm{Y}_{2}, \mathrm{Y}_{3}$ (impact hammer tests). 


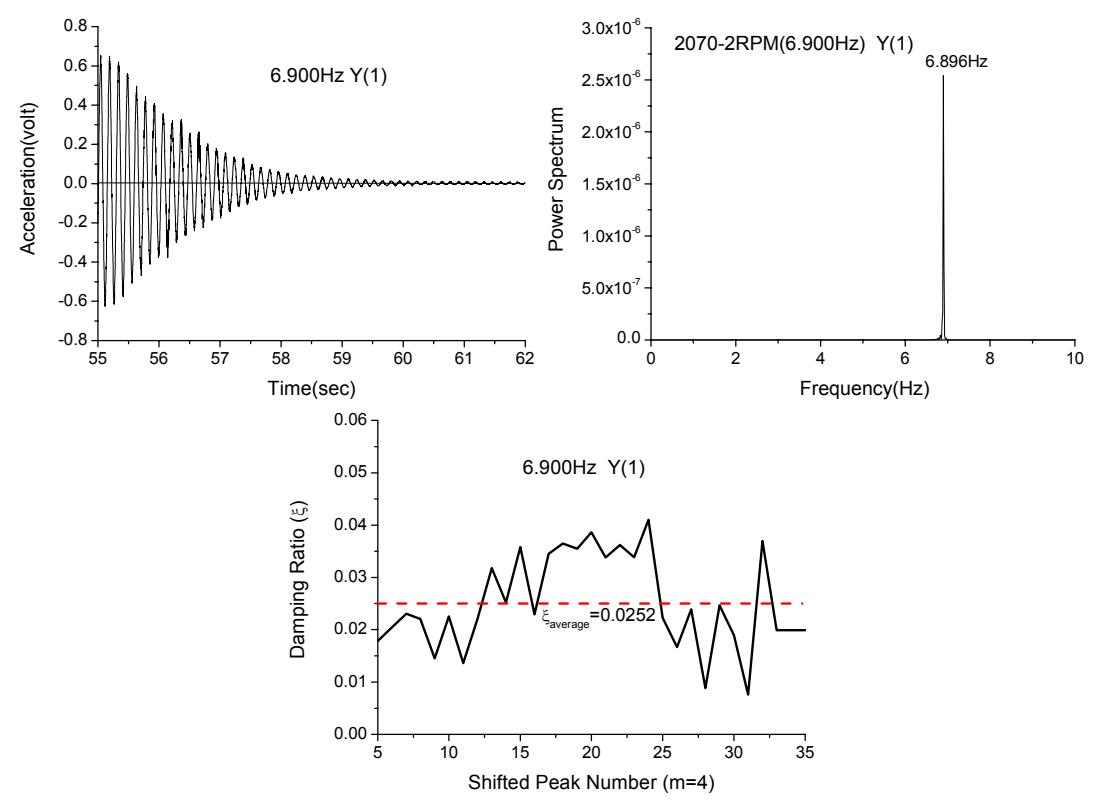

Figure 3: Free vibration response, APSD function at $\mathrm{Y}_{2}$ and damping ratio (vibration exciter tests).

Table 2: $\quad$ The $1^{\text {st }}$ natural frequency and damping ratio from experiments and analysis.

\begin{tabular}{c|c|c|c|c|c}
\hline & \multicolumn{2}{|c|}{$\begin{array}{c}\text { Impact Hammer } \\
\text { Tests }\end{array}$} & \multicolumn{2}{c|}{$\begin{array}{r}\text { Resonance Tests by Vibration } \\
\text { Exciter }\end{array}$} & $\begin{array}{c}\text { Free Vibration } \\
\text { Analysis }\end{array}$ \\
\cline { 2 - 6 } & $\begin{array}{c}1 \text { st } \\
\text { Bending } \\
\text { Frequency }\end{array}$ & $\begin{array}{c}\text { Damping } \\
\text { Ratio }\end{array}$ & $\begin{array}{c}1 \text { st } \\
\text { Bending } \\
\text { Frequency }\end{array}$ & Damping Ratio & $\begin{array}{c}\text { 1st Bending } \\
\text { Frequency }\end{array}$ \\
\hline TEST I & $6.95 \mathrm{~Hz}$ & $2.19 \%$ & - & - & $6.02 \mathrm{~Hz}$ \\
\hline TEST II & $7.32 \mathrm{~Hz}$ & $1.25 \%$ & $6.73 \mathrm{~Hz}$ & $2.68 \%$ & - \\
\hline $\begin{array}{c}\text { TEST } \\
\text { III }\end{array}$ & $7.45 \mathrm{~Hz}$ & $2.70 \%$ & - & - & - \\
\hline $\begin{array}{c}\text { TEST } \\
\text { IV }\end{array}$ & $7.45 \mathrm{~Hz}$ & $1.43 \%$ & $6.90 \mathrm{~Hz}$ & $2.57 \%$ & $6.79 \mathrm{~Hz}$ \\
\hline
\end{tabular}

Table 2 summarizes the results of each experiment, and shows the fundamental frequencies in flexural mode and the damping ratio of the $25 \mathrm{~m}$ full scale IPC girder model. It was found that the natural frequency from Test II had an increase of $5.32 \%$ before the composition of the deck. In addition, from a comparison of Test II and Test IV, through a tensioning of the upper tendon, an increase of $1.78 \%$ in the impact test and an increase of $2.53 \%$ in the resonance 
test were found. This result coincides with other theoretical and experimental studies concerning the effects of prestressing on the stiffness of structures (Dall'asta and Leoni [2], Saiidi et al. [5]).

In the free vibration analysis that was done before the tests, the first bending frequency appeared at $6.01 \mathrm{~Hz}$ in Test I which was for a PSC beam-only, and $6.79 \mathrm{~Hz}$ in Test IV which was for a complete IPC girder state. The result of the free vibration analysis agrees well with the vibration exciter tests, and the impact hammer test shows relatively higher values of natural frequencies. A compressive strength of $430 \mathrm{MPa}$ for a test specimen is similar to the design compressive strength of $400 \mathrm{kgf} / \mathrm{m}^{2}$, and the additional weight by the vibration exciter is exceedingly small compared to the total weight of a $25 \mathrm{~m}$ full-sized model. Therefore, it can be expected that the resonance test by vibration exciter is more credible than the impact hammer test.

In order to verify these results, an impact hammer test (Test V) with additional accelerometers to acquire more detailed mode shapes of the model was conducted. From the result of Test V, it was found that the overall exciting force of impact hammer was insufficient for a massive $25 \mathrm{~m}$ full scale model, and the first bending mode shape of the test model cannot be found accurately by the impact hammer tests. Therefore, the natural frequency from the impact hammer test results in higher values than the resonance tests by the vibration exciter. This can be explained in figure 4 which shows the effective length of the model. As expected, in the impact hammer test, a higher frequency must appear, as the first bending frequency is evaluated from an effective length of $22.07 \mathrm{~m}$.

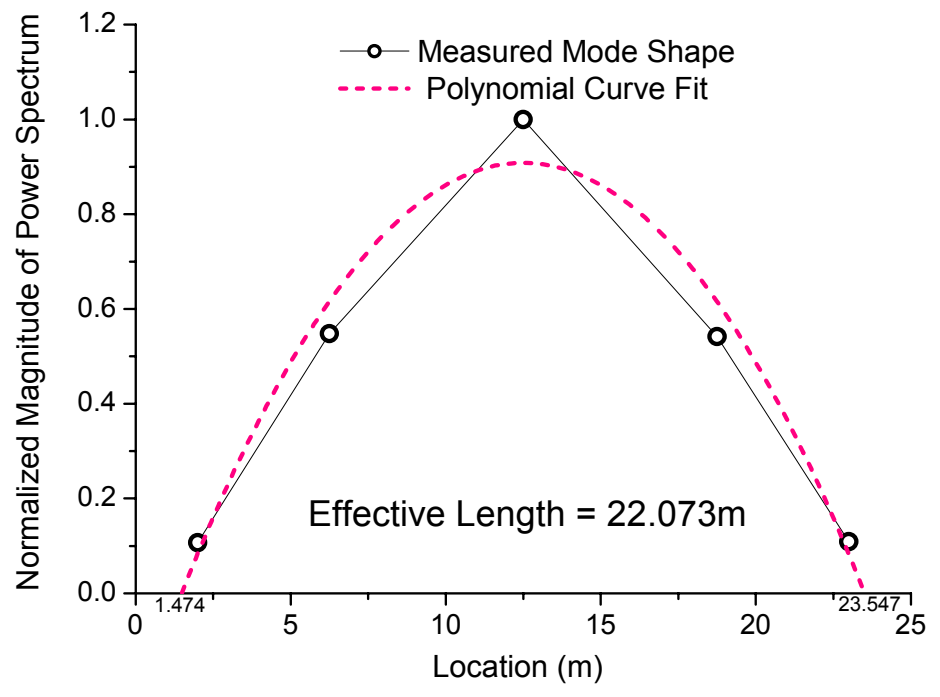

Figure 4: Curve fitting of the effective length of test model from the impact hammer test. 
In order to estimate the damping ratio, it can be said that the logarithmic decrement method is more reliable than the half-power bandwidth method. In the present study, the damping ratio from a resonance test can be accepted as producing more reliable values, as the damping ratio tends to increase as the deformation of structure increases. However, the damping ratio varies with the acceleration response, indicating that the acquired free vibration response does not show exponential decay accurately. Therefore, the average value of several damping ratio is selected to representative the damping ratio for the test model. Finally, it can be concluded from Test IV that an IPC girder in the final stages has a damping ratio of $2.5 \%$, as shown in figure 3 .

Consequently, the natural frequency of an IPC girder from the experiments has error of $1.62 \%$ comparing with the analysis. From this result, it can be concluded that the sectional and material properties of design values can be used for estimating dynamic performance. Conversely, a damping ratio of $2.5 \%$ would be adequate. These results from the modal tests can be used as credible input data for a dynamic analysis under moving train loads.

\section{Conclusion}

An estimation of the dynamic performance of railway bridges which undergo a uniform interval of axles and repetitive moving forces induced from the passing train is very important and it is essential for a newly developed bridge that have been designed with more flexibility. The sectional and material properties of design values can have a number of differences from the actual constructed values, and the damping ratio of the structure cannot but particularly depend on such an assumption. An understanding of the exact dynamic behavior of a railway bridge should be undertaken from the exact modal properties of the bridge to be considered.

In this paper, a full scale IPC girder of 25 meters long as a test specimen was fabricated, and modal testing on it at every construction stage was carried out in order to evaluate the modal parameters, including the natural frequency and the modal damping ratio. During the modal testing, a digitally controlled vibration exciter and the impact hammer were utilized in order to obtain the frequency response functions more precisely. In addition, the modal parameters were evaluated varying through various construction stages.

Various parametric studies on the dynamic behavior under the passage of a moving train can be performed for an estimation of the dynamic performances of an IPC girder railway bridge with the modal properties from the experiments.

a. It can be known from the modal tests that the impact hammer test can overestimate the natural frequency of the structure. The effective length of the fundamental mode of the structure can be shortened if the vibrating force against the experimental model is insufficient. The damping ratio also appears to increase as the deformation of structure increases. Therefore, a damping ratio from a resonance test can be accepted as producing more reliable values. In the present study, the 
average value from experimentally produced damping ratios was selected as a representative damping ratio for the test model. Consequently, it can be concluded that a resonance test by a vibration exciter is more credible than impact hammer tests, and that attention is required if using an impact hammer in modal tests.

b. The natural frequency of an IPC girder from the experiments has an error of $1.62 \%$ compared to the analysis. From this result, it can be derived that the sectional and material properties of the design values can be adequate for the dynamic performance estimation. On the other hand, a damping ratio of $2.5 \%$ is adequate for the dynamic performance estimation.

c. The effects of prestressing on the stiffness of structures can be founded at every prestressing stage. This result coincides with other theoretical and experimental studies concerning the effects of prestressing on the stiffness of structures. However, further theoretical and experimental studies referring to this problem should be conducted for a more detail discussion.

\section{References}

[1] Bendat, J. S. and Piersol, A. G., Random Data: Analysis and Measurement Procedures ( ${ }^{\text {rd }}$ Ed)., John Wiley \& Sons, Inc., 2000.

[2] Dall'asta, A. and Leoni, G., Vibrations of Beams Prestressed by Internal Frictionless Cables, Journal of Sound \& Vibration, 222(1), pp. 1-18, 1999.

[3] Fryba, L., Vibration of Solids and Structures under Moving Loads, Noordhoff International, 1972.

[4] Kwark, J.W., Choi, E.S., Kim, Y.J., Kim, B.S. and Kim, S.I., Dynamic Behavior of Two Span Continuous Concrete Bridges under Moving HighSpeed Train, Computers \& Structures, 82(4-5), pp. 464-474, 2004.

[5] Saiidi, M., Douglas, B., and Feng, S., Prestress Force Effect on Vibration Frequency of Concrete Bridges, ASCE Journal of Structural Engineering, 120(7), pp.2233-2241, 1994.

[6] Yang Y.B., Yau J. D. and Hsu L.C., Vibration of Simple Beams due to Trains Moving at High Speeds, Engineering Structures, 19(11), pp.936944, 1997. 